\title{
Study on the Hui People and Islam in Yongping County around Ancient Bonan Route
}

\author{
Rongtao Yang ${ }^{1,}$, , Lijuan Ding ${ }^{2}$ \\ ${ }^{1}$ Institute of Religious Studies, Sichuan University, Chengdu, Sichuan Province, China \\ ${ }^{2}$ Chongqing Vocational Institute of Tourism, Qianjiang, Chongqing City, China \\ ayrt1987@aliyun.com
}

Keywords: Ancient Bonan Route; Yongping County; the Hui People; Islam; Religious Culture Interchanges.

\begin{abstract}
As a county around ancient Bonan Route belonging to the Southern Silk Road, Yongping in West Yunnan historically was an area of cultural interchanges among Han, Yi, Bai and other ethnic groups. Since Yuan, Ming and Qing dynasties, Islam has spread in this area with the entrance of Hui migrants. Yongping County became a cultural interchanges area for both multiple ethnic groups and multiple religions, including Han, Bai, Hui, Yi ethnic groups and Confucianism, Taoism, Buddhism, Islam, which is a representative of religious culture interchange in China society. In the present paper, the author concludes that the ancient Bonan Road belonging to the Southern Silk Road is not only an important Ethnic migration corridor, but also an important channel for dissemination and communication of religious culture.
\end{abstract}

\section{Introduction}

As a county lies in the Tibetan-Yi Corridor, Yongping historically was an area of cultural interchanges among Han, Yi, Bai and other ethnic groups. Yongping is the centre county around the Bonan Route belonging to the Southern Silk Road which is an important sino-foreign economic and cultural exchange aisle starting from Chengdu China and ending in countries like Myanmar,India, etc. Since Yuan, Ming and Qing dynasties, With the Hui people moving into the county, Yongping has become a multi-ethnic converging place including Han,Yi,Hui,Bai and other nationalities. This article takes the exchange and integration of ethnic groups and religious culture in the Southern Silk Road as research view to probes into the historical position of the Hui people and Islam in Yongping county.

\section{The Hui Migration in Bonan Route since Yuan,Ming and Qing Dynasties}

Yongping is a county in west of the Bai Autonomous Prefecture of Dali. It is surrounded by Yi Autonomous County of Yangbi, Yi and Hui Autonomous County of Weishan, Changning County, Baoshan City and Yunlong County. The Bonan Route is named after the Bonan Mountain which is about twenty kilometers away from the Yongping County, where the Southern Silk Road goes through. The Yongping County is called the throat of the Southern Silk Road which is not easy to pass because of the high Bonan Mountain and deep Langcang River. In the twelfth year of Yong Ping (AD69), the chief of the Ailao tribe called Liumao sent his son to submit to the Emperor Mingdi in Eastern Han Dynasty. The court divided the area belonging to the Ailao tribe into Ailao and Bonan, which were under the control of Yongchang. In the eleventh year of ZhiYuan(AD1274)in Yuan Dynasty, the Yuan court named the area Yongping county.

In the first year of BaoYou(AD1253)in Southern Song Dynasty, Kublai on behalf of about 100000 army successfully conquered the Kingdom of Dali .In AD1254, Kublai went back to the north with part of his army and had Uriyangqatai continue to attack the ethnic tribes in Dali. There were many Huihui among Uriyangqatai's army which were from Khwarezmia, Khalifa Bahattah and other places in Central Asia. When the war was over, some soldiers were registered to guard along the road. In the seventeenth year of ZhiYuan(AD1280)to the first year of DaDe(AD1297)in Yuan Dynasty, the 
commanders including Nestardin and AriqQaya leading Mongolia Army and Allied Army conquered Myanmar. After the war, there were about 14000 Hui soldiers backed to land reclamation in Yongchang, Dali and other places. According to research statistics, there were about 100000 Huihui soldiers and craftsmen entered Yunnan in Yuan Dynasty. And some of them stayed in Yongping.

In the fourteenth year of HongWu(AD1381)in Ming Dynasty, Zhu Yuanzhang appointed Fu Youde,Muying and Lanyu to attack Yunnan with 300000 troops. They successfully conquered Kunming, Ling'an, Chuxiong, Dali, Heqing, Lijiang, Goldenteeth, Cheli,Burma. In the fifteenth year of HongWu(AD1382), the army of Ming Dynasty basically conquered the whole territory of Yunnan, and the Ming court set up administrative agencies, defensive buildings, post houses, etc. There were some Hui soldiers and settlers staying in Yongping county. During the years of ZhengTong in Ming Dynasty, Commander Wangji attacked Luchuan three times(AD1441、1442、1448).After his success, 200000 soldiers were left to reclaiming and guarding in west Yunnan. A large amount of Hui soldiers from northwest China and south of the Yangtze River settled in Yongping. In the twelfth year of HongWu(AD1379), the Ming court appointed Ma Suofei who was a Hui people as local tyrant to administrate the Hui people in Yongping. The case reflected that lots of Hui people were in Yongping.

In early and mid period of Qing Dynasty, the government encouraged mainlanders to immigrate and reclaim in Yunnan. The number of the Hui people increased. Before 1873, there were about 40000 Hui people living in 32 villages in Yongping. After the failure of Du Wenxiu Upring,the amount of Hui people in Yongping dropped to about 1000.

During the Republic of China, the number of Hui people in Yongping increased. More than 8000 Hui people in 1000 families distributed widely over Qudong, Yinjiang,Longjie,Shayang,Linghua,etc.

After the establishment of People's Republic of China, the growth rate of Hui population was rapid in Yongping. By January 1953, the number of Hui peole had been 5861 which accounted for 8\% of the total population in Yongping and distributed in 16 townships. By 1985, 10434 Hui people had distributed in 18 townships. According to the statistics of the fourth national census, there were 11675 Hui people in Yongping which accounted for $7.42 \%$ of the total population. According to the statistics of the fifth national census, there were 13581 Hui people in Yongping which accounted for $8 \%$ of the total population. By the end of 2005, the county's total Hui population had been 14290 which accounted for $8.18 \%$ of the total population. By the end of 2014, the number of Hui people had been 14707 which accounted for $7.91 \%$ of the total population and ranked the third less than the number of Han people and Yi people.Now, The Qudong village is the largest among the Hui people villages and there are more than 7000 Hui people in the village.

\section{Mosques and Education of Hui People in Yongping County}

Since Yuan,Ming and Qing Dynasties, the Hui people in Yongping has scattered a pattern with large distribution and small centralization. And they live around the mosques. In the fifteenth year of HongWu(AD1382),Ma Guodong who was the eighth generation grandson of Al-Sayyid Shams built a mosque, which was the earliest mosque in Yongping. Latter two mosques (one big, one small) were constructed at the south gate of the Great Grave and below the Little Lion Mountain (construction year unknown).In the tenth year of Tong Zhi(AD1871)in Qing Dynasty, the small mosque was destroyed and the big mosque remained ratty. In the second year of Republic of China(1913), the Hui people constructed one mosque at the site of the big and small mosques. Qudong mosque was listed at the first batch county-level cultural relics protection units. In 1990, the Muslim of Qudong built the minaret and gate, which was a scale and covered area about 4500 square meters. Yongping Islamic Association was in it.

The Culture City of Hui People in Qudong on top of the Little Lion Mountain was completely constructed in 2013. The mosque was the landmarks of the entire culture city, and the hall for prayer was the central building of the entire culture city. The hall present the elements combined Chinese-Arabic ethnic culture. Nearly 3000 people can accommodate in the first layer, and the 
second layer can be used to organize various activities. There are cultural corridors of Qudong Hui people on the left side of the hall. The Historical Cultural Exhibition Centre and Huifeng Scripture School of Qudong Hui people are behind the hall. In addition, there is worship area for women and special trade zones are set around the hall.

By 2016, there had been 26 mosques in Yongping. The specific distribution was as form below.

\begin{tabular}{|c|c|c|c|}
\hline order & town & amount & rate \\
\hline 1 & Bonan & 11 & $42.3 \%$ \\
\hline 2 & Longjie & 8 & $30.8 \%$ \\
\hline 3 & Changjie & 4 & $15.4 \%$ \\
\hline 4 & Longmen & 3 & $11.5 \%$ \\
\hline
\end{tabular}

After the establishment of People's Republic of China, especially since 1980s, the number of mosques in Yongping has reached the scale (25 mosques) before 1873. Administrative Committees are set in mosques. The Yongping Islamic Association guide the Administrative Committees' work, such as construction, maintenance, festivals, weddings, death, mosque education, etc. These mosques are not only signs that the Hui people have immigrated and settled in Yongping, but also symbols that Islam has spread with the Hui's immigration.

The mosque education is an important way to cultivate the successors of Islamic culture. During the years of QianLong, Ma Chengxiao had taught many outstanding successors of Islamic culture in Qudong Arabic College. He was a respected and unforgettable imam. Middle schools and primary schools are commonly set as long as mosques existed, teachers teach how to read and chant the Koran, and teachers explain the Six Beliefs and the Five Pillars. In addition, supplementary classes (in the morning, evening or holiday, etc. ) are set to those who do not accept the mosque education or are lack of Islamic Knowledge.

The mosque education in Qudong Chinese-Arabic School is a typical example. The school opens up classes for imam and old Muslim and offers Arabic courses (phonetic, words, grammar) and pistology courses, etc. By 2016, there had been nearly 270 imams in Yongping. They rendered worship, marriage, funeral culture and Islamic clergy service to villages and they played important roles in dealing with Islam affairs and developing Muslim social cultures.

The Huifeng Scripture School lies on top of the Little Lion Mountain, with Qudong Chinese-Arabic School being its predecessor. The Huifeng Scripture School has a strong faculty. Some teachers have studied in Egypt, Sultan, Medina, Malaysia and other places, and some have taught in Arabic school abroad. According to the standard of age and gender, the school offers full time classes for young people, classes for young women, classes for middle and old aged men and women. The school regularly recruits students from the community and provide tuition fees, free meals and accommodation, as well as national scholarships, employment. Outstanding students will have opportunities to study in Arabia. The school open courses containing Arabic, science, ethnology, Koran, etiquette, modern Chinese legal system, computer, etc. The school will continually play an important role in the transmission and spread of Islamic culture.

Along with the country's religious policy being fully implemented, the mosque education in Yongping has achieved access. The mosque education has played a positive role in inheriting traditional culture and training management personnel and other aspects of Islam.

\section{Thinking the Relationship between the Islam and the Culture of Yongping County}

The Hui people in Qudong, Longjie, Changjie, Longjie mainly believe in the Qadim of Sunni in Islam. The local people call it "old denomination". They approve the Six Beliefs of Islam, namely belief in Allah, Angel, Sage, Classic, Judgment and Afterlife. At the same time, the Hui people in Yongping strictly abide by the Five Pillars, namely read, chapel, fast, alms and pilgrimages. By 2016, more than 55 Muslims have pilgrimaged to Mecca and acquired the glorious "Hajis". Corban and Mawlid are important festivals for Muslims. During these festivals, Muslims slaughter cattle to sacrifice Allah gathering in mosques. They also make traditional foods, like Sangzi, Youxiang, Pop 
rice Candy, Ersi, etc. The people dressed in costumes call on friends and relatives and share rich food together. They take part in a series lively activities held by Administrative Committee.

Confucianism, Buddhism and Taoism have had deep influences on the local people's spiritual life since Ming and Qing Dynasties. There were different kinds of religious activities facilities. Some records about the facilities can be found in Local Chronicles. There was a Confucius Temple in east of the Confucian Teaching Building in Ming Dynasty. The Confucius Temple consecrated Confucius and Sages. People sacrificed them in strict procedures in Ding Day of annual spring and autum. Ritualists, offerings and utensil were in grand standard. There was one Zhen Wu Temple in Yongping during the Ming Dynasty, and the temple sacrificed the Zhen Wu God, which was an important god in Taoism. There was a Yuhuangge in north of the Yongping County, which was 10 miles away from the county. There was a Sanqing Temple in west of the county, which was 10 miles away from Yongping. Those Taoism temples reflected that Taoism affected the society of Yongping deeply. There were two Kwan-yin temples in Yongping, which presented that beliefs in Kwan-yin was popular in Yongping . One was built in the Ming Dynasty in west 1 mile away from the county. The other was constructed in Kwan-yin Mountain by the villagers in the thirtieth year of QianLong(AD1765) in Qing Dynasty, which was in north 30 miles away from the county.

The Islam has been spread widely in Yongping with the Hui immigrants since Yuan, Ming and Qing Dynasties. A situation of coexistence of multiple religions containing Buddhism, Taoism, Bimo, Acarya and Islam was formatted.

\section{Conclusion}

All in all, the ancient Bonan Road belonging to the Southern Silk Road is not only an important Ethnic migration corridor, but also an important channel for dissemination and communication of religious culture. Since Yuan, Ming and Qing dynasties, With the Hui people moving into the county, Yongping has become a multi-racial converging place including Han,Yi,Hui,Bai and other nationalities. The studied case in this paper is a representative of religious culture interchange in China society. It is worthwhile to probe into the regional religious cultural relationships after researching the immigration of the Hui people, mosques, mosque education and Hui cultural celebrates.

\section{References}

[1] Yang Zhaojun edited: The History of Hui Nationality in Yunnan (Revised Edition), Kunming:Yunnan nationality press, 1994.

[2] Editorial Group of Yunnan Province edited: Investigation of the Social History of Hui Nationality in Yunnan, vol(1th,2th)Kunming:Yunnan national press, 1985.

[3] Yongping Bureau of ethnic and Religious Affairs edited: Yongping County Ethnography, Kunming:Yunnan national press, 2006.

[4] Zhengyu,Chenwen compiled: JingTai YunnanTuJingZhiShu, engraved edition of the sixth year of JingTai(1455).

[5] Li Zhongxi compiled: WanLi YunnanTongZhi, reprinted edition of the twenty-third year of Republic of China (1934).

[6] Xuan Shitao compiled: QianLong YongChangFuZhi, engraved edition of the fiftieth year of QianLong(1785).

[7] Fang Guoyu edited:Yunnan Historical Collections ,vol (4th), Kunming: Yunnan University press, 1998.

[8] Ma Xingdong: Exploration of Hui Nationality in Yunnan Province, Journal of Yunnan University for Nationalities, Issue(4th), 1988. 
[9] Li Rongkun: The Spread of Islam in Yunnan Province, China Muslim, Issue(3th), 1990. 